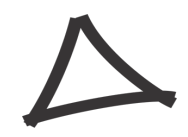

Revista Triângulo

ISSN 2175-1609

\title{
CONCEITO DE FORMAÇÃO DE PROFESSORES E DESENVOLVIMENTO PROFISSIONAL: SUAS DIFERENTES EXPRESSÕES E CONCEPÇÕES
}

\author{
CONCEPT OF TEACHER EDUCATION TRAINING AND PROFESSIONAL DEVELOPMENT: ITS \\ DIFFERENT EXPRESSIONS AND CONCEPTIONS
}
CONCEPTO DE FORMACIÓN DE PROFESORES Y DESARROLLO PROFESIONAL: SUS DIFERENTES EXPRESIONES Y CONCEPCIONES

Aline Tatiane Evangelista de Oliveira E-mail: alineevangelista@uniaraxa.edu.br Centro Universitário do Planalto Norte de Araxá - UNIARAXÁ

\begin{abstract}
RESUMO
O presente trabalho tem como objetivo discutir sobre os temas "Formação de Professores" e "Desenvolvimento Profissional Docente (DPD)" por meio de pesquisa bibliográfica. Inicia-se com uma análise sobre os temas a partir dos autores Marcelo Garcia (1999) e Fiorentini e Crecci (2013). Aponta as ideias principais discutidas pelos autores, busca estabelecer relações entre as suas diferentes dimensões e procura discutir as inúmeras expressões que foram e ainda são usadas para representar a formação de professores. Uma pergunta chave, levantada por Fiorentini e Crecci (2013), em relação à formação de professores, instigou-nos a debruçar sobre tais temas: "O DPD é um termo-guarda-chuva ou um novo conceito?". Observa-se que independentemente da expressão ou termo usado para nos remeter à formação do professor ou ao desenvolvimento profissional, o mais importante são mudanças relacionadas às políticas públicas que as organizam e as promovem; bem como a conscientização dos professores em relação a tal conceito.
\end{abstract}

PALAVRAS-CHAVE: Formação. Formação Docente. Desenvolvimento Profissional Docente.

\section{ABSTRACT}

The present work has the objective of discussing the topics "Teacher Training" and "Professional Teacher Development (DPD)" through bibliographic research. It begins with an analysis on the themes from the authors Marcelo Garcia (1999) and Fiorentini and Crecci (2013). It points out the main ideas discussed by the authors, seeks to establish relationships among their different dimensions and seeks to discuss the numerous expressions that have been and are still used to represent teacher education. A key question, raised by Fiorentini and Crecci (2013), related to teacher training, instigated us to address such themes: "Is DPD an umbrella term or a new concept?" It is observed that regardless of the term or term used to refer us to teacher training or professional development, the most important are changes related to the public policies that organize and promote them; as well as the teachers' awareness of this concept.

KEYWORDS: Formation. Teacher Training. Professional Development Teacher.

\section{RESUMEN}

El presente trabajo tiene como objetivo discutir sobre los temas "Formación de Profesores" y "Desarrollo Profesional Docente (DPD)" por medio de la investigación bibliográfica. Se inicia con un análisis sobre los temas a partir de los autores Marcelo Garcia(1999) y Fiorentini y Crecci (2013). En el caso de los profesores, se trata de establecer las relaciones entre sus diferentes dimensiones y tratar de discutir las numerosas expresiones que han sido y todavía se utilizan para representar la formación de profesores. Una pregunta clave, planteada por 
Fiorentini y Crecci (2013), en relación a la formación de profesores, nos instigó a abordar estos temas: "El DPD es un término-paraguas o un nuevo concepto?". Se observa que independientemente de la expresión o término usado para referirse a la formación del profesor o al desarrollo profesional, lo más importante son cambios relacionados con las politicas públicas que las organizan y las promueven; así como la concientización de los profesores en relación con dicho concepto.

PALABRAS-CLAVE: Formación. Formación docente. Desarrollo Profesional Docente.

\section{INTRODUÇÃO}

Ao analisar o atual cenário do processo ensino-aprendizagem predominante nas escolas atuais, verifica-se que muitos professores ainda adotam a postura do professor como transmissor do conhecimento; utilizando-se dos mecanismos pedagógicos de maneira linear; posicionando-se dentro dos modelos da racionalidade técnica: Apesar de as exigências atuais e dos mais variados discursos se pautarem no professor reflexivo, na ênfase da relação teoria/prática, percebe-se que eles são formados para serem profissionais técnicos e para atuarem a partir desse modelo nas escolas em que trabalham.

Ser professor, na contemporaneidade, conforme Mello e Lugle (2014) afirmam, é ser o docente um criador de motivos para que o aluno supere suas capacidades, em uma participação colaborativa na apropriação do conhecimento. Ele deve ser um mediador do processo ensinoaprendizagem, que conduza o discente a se apropriar da cultura acumulada a fim de que possa relacionar conhecimentos cotidianos e científicos por meio de práticas pedagógicas, alicerçadas em teorias; e, que, especialmente, promova a contextualização, a provocação, a instigação para que o aluno adquira e desenvolva a sua autonomia, sua participação ativa e seu pensamento curioso e crítico. Todavia, o que se nota nesse cenário, é algo completamente diverso.

$\mathrm{Na}$ trilha dessa reflexão, adentramos em uma questão, considerada uma das mais desafiadoras: a da formação de professores e o desenvolvimento profissional docente, suas possibilidades, particularidades e incongruências. Para Mello e Lugle (2014), tal cenário poderia ser um meio para superar as incoerências presentes no trabalho docente; pois, segundo

\footnotetext{
* Racionalidade Técnica: Uma atividade técnica e instrumental, porque decorre da aplicação do conhecimento sistemático e normativo, a prática pedagógica passa a ser entendida como neutra e isenta de subjetividade. (ALMEIDA, 2001, p.02).
} 
eles, seria esse o momento propício para que o professor passasse a pensar e a reformular as suas práticas pedagógicas.

Partindo dessa premissa, acreditamos que a busca pela formação continuada deva estar sempre presente na carreira docente; já que, consideramos que o professor quanto mais qualificado, mais bem preparado ele estará para enfrentar os desafios que decorrem de sua profissão. Entretanto, há de se questionar: este será o único caminho a ser trilhado? Percebemos que não seja o único, mas, essencialmente, o docente deverá percorrer essa trilha para que consiga atingir os objetivos desejados. Vale afirmar que a Educação Continuada é e continuará sendo um mecanismo para se alcançarem patamares melhores na prática docente.

Em relação à formação docente, observamos uma preocupação crescente por parte das Secretarias de Estado, do próprio PNE (Plano Nacional da Educação), o qual dedica quatro, de suas vinte metas, ao professor. Tais metas estão relacionadas à formação inicial, continuada, plano de carreira e valorização profissional. Todavia, há de se questionar: Como deve acontecer essa formação? O Desenvolvimento Profissional e a Formação Continuada se aproximam em seus significados? Ou são divergentes?

Nessa linha de raciocínio, a proposta desse trabalho é discutir, à luz de autores como Marcelo Garcia (1999) e Fiorentini e Crecci (2013), os conceitos, tanto da Formação Continuada, quanto do Desenvolvimento Profissional ou de vários outros termos que aparecem de tempos em tempos nas diferentes propostas de estudos como também em políticas públicas, presentes em relatórios ou documentos referentes à Educação, utilizados para representar a formação docente.

Assim, organizamos esse estudo em duas partes. Na primeira, enfocaremos o conceito de Formação e de Formação de Professores. Para um melhor entendimento sobre a teoria a ser pautada, elaboramos um Mapa Conceitual* (FIGURA 1), como ferramenta para que se possa

\footnotetext{
* Mapa Conceitual, conforme Silva (2007), são estruturas esquemáticas que representam conjuntos de ideias e conceitos dispostos em uma espécie de rede de proposições, de modo a apresentar mais claramente a exposição do conhecimento e organizá-lo segundo a compreensão cognitiva do seu idealizador. Para a elaboração de um Mapa Conceitual são necessárias várias leituras de textos; sendo importante o entendimento claro das principais ideias do autor; podendo, assim, fazer uma rede de elementos que se relacionam de maneira coerente para proporcionar a construção do conhecimento. Para a construção desses Mapas Conceituais, utilizamos o software livre "Cmaptools" (https://cmaptools.softonic.com.br/), por ser uma ferramenta simples e de fácil manipulação.
} 
fundamentar e entrelaçar as principais ideias apresentadas pelos autores. Em seguida, avançaremos no sentido de discutir sobre o Desenvolvimento Profissional de Professores, suas diferentes conotações e contextos. Também, adotamos o Mapa Conceitual (FIGURA 3), por considerar, conforme Veiga (2013, p. 43), como técnica de ensino-aprendizagem. Para ele, o Mapa Conceitual "é uma técnica de ensino, aprendizagem, pesquisa e avaliação, inspirada na perspectiva histórico-crítica de educação". Ao finalizar o estudo em pauta, apresentamos as conclusões, mesmo que temporárias, construídas a partir dos estudos.

\section{REFERENCIAL TEÓRICO}

\subsection{A Formação e a Formação de professores}

A Formação Inicial, normalmente, é entendida como aquela realizada em Instituições de nível superior (Graduações,) em diferentes áreas; e, a Formação Continuada é aquela que é realizada após a Formação Inicial. A Formação Continuada pode ocorrer concomitantemente à atuação profissional, chamada de "Formação Continuada em Serviço".

Atualmente, o profissional, de modo geral e principalmente o profissional docente, deverá estar consciente de que a sua formação é permanente e deverá estar integrada ao seu dia-a-dia, especialmente, nas escolas; como lembra Alvarado Prada (1997, p.99). “A formação’ implica a contextualização do professor num meio cultural, visando à transformação do mesmo". Entretanto, há alguns anos, apenas a conclusão da Graduação era o bastante para a atuação profissional e era considerada o ponto final para qualquer pessoas que desejasse entrar e permanecer na sua área profissional; o que seria impensável nos dias atuais, dadas às circunstâncias de contemporaneidade e de globalização que vivenciamos atualmente.

Percebemos que, na última década, vários movimentos se efetivaram, direcionados a repensar a formação de profissionais do Magistério da Educação Básica, incluindo questões e proposições atinentes à valorização desses profissionais. Vale destacar aqui que a valorização da docência como política educacional depende das políticas macroeconômicas vigentes, com intuito de reverter o processo de precarização do trabalho do professorado; considerada um dos 
entraves para a melhoria da qualidade da Educação Brasileira.

No âmbito do Conselho Nacional de Educação (CNE), houve uma movimentação em torno da busca por maior organicidade para a formação desses profissionais. Ressalta-se que as deliberações da CONAE (Conferência Nacional de Educação), cumpriram um papel singular nesse processo, especificamente, ao destacar a articulação entre: O Sistema Nacional de Educação e as políticas e a valorização dos profissionais da Educação. Dourado (2015, p.301) vem a corroborar com tal afirmativa, salientando

Ao reafirmar uma base comum nacional para a formação inicial e continuada cujos princípios devem ser considerados na formulação dos projetos institucionais de formação inicial e continuada - incluindo a licenciatura (...)

Segundo o autor, os projetos institucionais elaborados para a formação de profissionais da Educação deveriam estar fundamentados em uma base comum a fim de que todos os docentes pudessem ter acesso a essa formação de forma equânime e igualitária.

A aprovação do Plano Nacional de Educação (PNE) 2014/2024 resultou na Lei ${ }^{\circ}$ 13.005/2014 que apresenta as diretrizes sinalizadoras em busca de uma maior organicidade para a Educação nacional, estabelece vinte metas prioritárias bem como várias estratégias para a efetivação de uma Política Nacional de Formação dos Profissionais da Educação.

Para um melhor entendimento sobre o conceito de Formação e de Formação de Professores, apresentados nas diversas propostas citadas anteriormente, debruçamo-nos sobre o trabalho de Marcelo Garcia (1999); e, a partir desse estudo, elaboramos um Mapa Conceitual, conforme mencionado em parágrafo deste texto. Este Mapa será apresentado como Figura 1. Nele, demos enfoque às principais teorias sobre a Formação e a Formação Inicial; entrelaçando ideias para facilitar a percepção e a compreensão dos referidos conceitos; e, principalmente, tentar buscar a construção do conhecimento sobre o tema em questão.

Figura 1 - Mapa Conceitual sobre a Formação e a Formação do Professor 


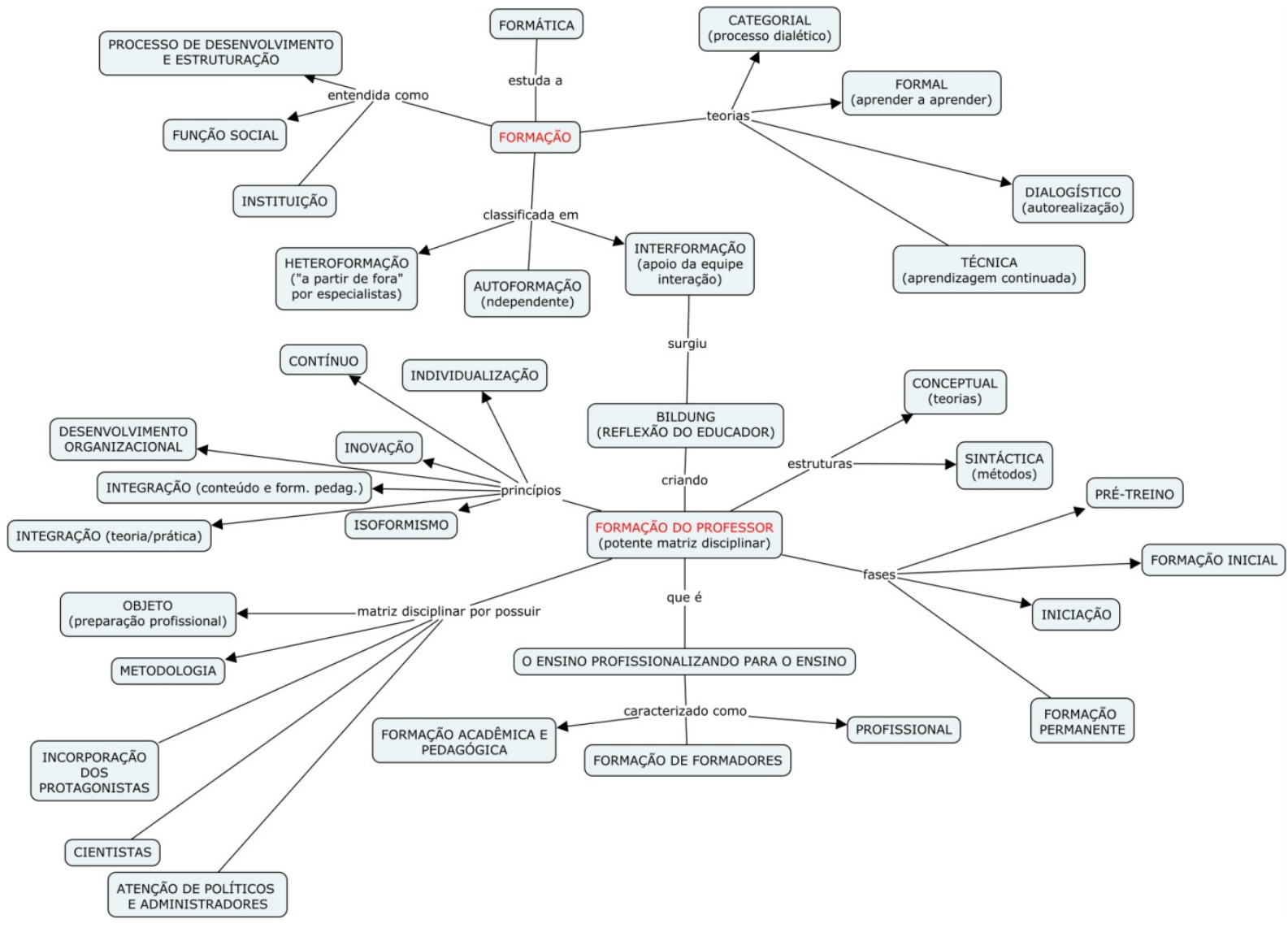

Fonte: Elaborado pela autora deste trabalho

A partir da reflexão sobre o proposto pelo Mapa Conceitual acima, tentamos destacar alguns pontos os quais consideramos merecer nossa atenção, com o intuito de aprofundar um pouco mais sobre as questões relacionadas à Formação e à Formação Docente.

Marcelo Garcia (1999) aponta que a "Formática" é a área do conhecimento que estuda a formação de maneira geral. Essa formação pode adotar diferentes aspectos (p. 19), "conforme se considera o ponto de vista do objeto (a formação que se oferece, organiza, exteriormente ao sujeito); ou, o do sujeito (a formação que se ativa como iniciativa pessoal)".

Para o autor, ela pode ser classificada em três diferentes maneiras, a saber: "Heteroformação" - é a formação realizada por especialistas, sem a intervenção do sujeito a ser formado; a "Autoformação" - em que o indivíduo participa de maneira independente; e, a Interformação - é aquela que acontece com a interação de equipes. Consideramos que seja nesse cenário da "Interformação" que surge a reflexão sobre a formação do educador, 
conhecida como "Bildung"; criando a chamada "Formação do Professor", a qual consiste na formação em que o ensino está profissionalizando o ensino.

Ao abordar essa temática sobre a formação do professor, verificamos que se trata de uma área em "processo de independência"; ou seja, possui um forte potencial de Matriz Disciplinar, por possuir um objeto de estudo, isto é, a preparação profissional; uma metodologia; e, pessoas que se envolvem e se preocupam com a área (cientistas, governantes e os próprios professores). Todavia, buscamos, novamente, em Marcelo Garcia (1999), o qual destaca que para ocorrer a formação docente, há de haver sete princípios fundamentais, os quais são tidos como importantes: Individualização (crescimento pessoal e profissional); Continuidade (processo em constante construção); Inovação (mudança para a melhoria da Educação); Desenvolvimento Organizacional (busca por melhorias para a Instituição em que trabalha);Integração (teoria/prática); Integração (conteúdo e formação pedagógica); e, Isoformismo (professor formado no mesmo espaço em que irá exercer a sua profissão).

O autor destaca, também, a formação do professor, que pode ser dividida em quatro fases: o "Pré-treino" (experiências do futuro professor como aluno da Educação Básica); a "Formação Inicial" (fase da Graduação, como comentado inicialmente); a "Iniciação" (os primeiros anos de experiência profissional como docente atuante); e, a "Formação Permanente" (conhecida Formação Continuada, que acontece ao longo da vida profissional). Assim, entendemos que a formação do professor não se inicia, necessariamente, na Graduação, mas, ela ocorre ao longo de sua vida escolar, perpassando pela Educação Infantil, indo à Educação Superior; pois, acreditamos que, em que todos esses os níveis, as pessoas trazem consigo suas concepções e influências, tanto de escolas como de professores.

Em suma, quando falamos sobre o tema "Formação do Professor", remetemo-nos a três questões: Ao Processo, que compreendem as propostas teóricas e práticas sobre o tema; À Área de Investigação, que consiste o campo de pesquisa; possuindo um objeto, uma metodologia e uma comunidade envolvida e ao Conjunto de Conhecimentos, entendido como uma Disciplina; que pode se tratar da escola, do aluno, do ensino e do próprio professor.

Após as discussões sobre a Formação do Professor, mergulharemos um pouco mais sobre o tema a fim de que possamos entender o assunto, dentro do campo, denominado "Desenvolvimento Profissional Docente (DPD)". Tal aprofundamento se dará a partir da leitura 
de diferentes autores.

\subsection{Desenvolvimento Profissional Docente}

Ao abordar a temática Desenvolvimento Profissional Docente (DPD), recorremos aos estudos de Marcelo Garcia (1999) e Fiorentini, Crecci (2013), os quais nos questionam e nos instigam a entender melhor esse conceito.

Segundo Marcelo Garcia (1999), todo profissional do ensino precisa de DPD. Necessita de um desenvolvimento que produz evolução, continuidade e contextualização, para que o professor esteja sempre em busca de uma atitude de questionamento, de permanente pesquisa; com vistas a solucionar problemas do seu dia-a-dia bem como para valorizar uma orientação rumo à mudança em seu caráter contextual e em seu caráter organizacional; isto é, um desenvolvimento profissional que contribua com o seu contexto e organização escolar.

Vários foram e são os termos e conceitos utilizados pelo estudioso no sentido de possibilitar a compreensão sobre o desenvolvimento profissional do professor. Termos e conceitos, tidos como apropriados; e, que foram discriminados até mesmo pelas políticas públicas em diferentes épocas; ou, muitas vezes, tratados como sinônimos. Para elucidar tal proposição, remetemo-nos, outra vez, a Marcelo Garcia (1992), que esclarece, Formação em Serviço (acontece depois de se formar e estando em serviço, ou seja, trabalhando); Formação Continuada (também em serviço, objetivando um desempenho mais eficaz); Reciclagem (ação de treino, quando um conhecimento fica obsoleto); Aperfeiçoamento.

Outros termos, também, já foram usados nesse mesmo sentido, como: Capacitação, Evolução, Mudança, etc. Tentando entender melhor tais conceitos, buscamos em Alvarado Prada (1997), que traz o detalhamento de cada expressão e elaboramos a seguir. 
Figura 2 - Diferentes Expressões referentes à Formação Docente

\begin{tabular}{|c|c|}
\hline Expressões & Significado \\
\hline Capacitação & Considera os docentes descapacitados ou incapacitados. \\
\hline Qualificação & Visa melhorar algumas qualidades já existentes. \\
\hline Aperfeiçoamento & Implica em tornar os professores perfeitos. \\
\hline Reciclagem & Termo próprio de processos industriais (lixo). \\
\hline Atualização & Informar, para mantê-los em atualidade. \\
\hline Formação Continuada & $\begin{array}{l}\text { Alcançar níveis mais elevados na Educação Formal ou } \\
\text { aprofundar os conhecimentos que já possuem (Atividades } \\
\text { de Extensão Universitária). }\end{array}$ \\
\hline Formação Permanente & $\begin{array}{l}\text { Visa à formação geral da pessoa, sem se preocupar apenas } \\
\text { com os níveis da Educação Formal. }\end{array}$ \\
\hline Especialização & Realização de um Curso Superior sobre um tema. \\
\hline Aprofundamento & Tornar mais profundos alguns conhecimentos. \\
\hline Treinamento & Adquirir uma habilidade por repetição. \\
\hline Retreinamento & Voltar a treinar o que já havia sido treinado. \\
\hline Aprimoramento & Melhorar a qualidade do conhecimento do professor. \\
\hline Superação & Subir a outros patamares, exemplo,Titulação Universitária. \\
\hline $\begin{array}{l}\text { Desenvolvimento } \\
\text { Profissional }\end{array}$ & $\begin{array}{l}\text { Procura por melhor desempenho profissional. Cursos de } \\
\text { curta duração que procuram a "eficiência" do professor. }\end{array}$ \\
\hline Compensação & Superar algo que falta. \\
\hline Profissionalização & Tornar profissional. Conseguir um diploma. \\
\hline
\end{tabular}

Fonte: Alvarado Prada (1997)

Partindo-se de todas as expressões e todos os conceitos definidos, retomamos o trabalho de Fiorentini e Crecci (2013) para elaborar as seguintes indagações: Pode-se considerar o 
conceito de Desenvolvimento Profissional Docente como um termo guarda-chuva ou seria um novo conceito? Trata-se de um termo que abriga todas as expressões e os conceitos que citamos anteriormente ou consiste em um novo conceito com características próprias e bem definidas? Para tentar responder a esses questionamentos, consideramos que haja necessidade de entender um pouco mais o que os autores apontam sobre o assunto.

Segundo Marcelo Garcia (1992), DPD pode acontecer em seis dimensões; as quais estão relacionadas ao caráter pessoal, ou seja, dimensões pedagógicas, teóricas, cognitivas e do conhecimento de si, sendo elas: o desenvolvimento teórico (reflexão sobre sua prática); o desenvolvimento cognitivo (aquisição de estratégias de ensino); o conhecimento de si mesmo (imagem equilibrada); o desenvolvimento pedagógico (centrado em áreas do currículo); o desenvolvimento profissional (investigação); e, o desenvolvimento da carreira (adaptação de novos papéis). Para o autor, tais dimensões podem ocorrer em quatro diferentes áreas de investigação: Para o currículo, busca de melhorias em questões relacionadas ao currículo escolar; Ao ensino, relacionadas ao processo ensino-aprendizagem; À escola, ligadas a sua estrutura; E ao professor, relacionando, por exemplo, plano de carreira e salário.

No entanto, para que isso realmente ocorra, é necessário que a escola tenha autonomia, seja para selecionar professores, organizar currículos; uma gestão democrática e participativa, que acredite na cultura de colaboração dos membros envolvidos e que tenha liderança instrucional, ou seja, uma equipe que impulsione e incentive os profissionais em serviço.

Se retornarmos ao Quadro (FIGURA 2), notaremos que Alvarado Prada (1997, p.89) esclarece que o desenvolvimento profissional poderia ser visto como a "procura de melhor desempenho profissional". Ademais, ressalta que Cursos de Curta Duração procuram a "eficiência" do professor". Assim, ele acredita que a expressão "Desenvolvimento Profissional" deva ser usada nos cursos de curta duração realizados com intuito do professor se tornar competente, produtivo e de conseguir melhor rendimento, seu e dos alunos. Em relação ao termo "formação", ele apresenta a "Formação continuada" e a "Formação permanente", sendo elas, segundo ele, possuidoras de aspectos similares.

Valendo-se, mais uma vez, da estratégia do Mapa Conceitual, optamos por elaborá-lo a partir do estudo de textos, cujas referências compõem este trabalho; propiciando, dessa maneira, sintetizar toda a discussão pautada até aqui. 
Figura 3 - Mapa Conceitual - Desenvolvimento Profissional Docente

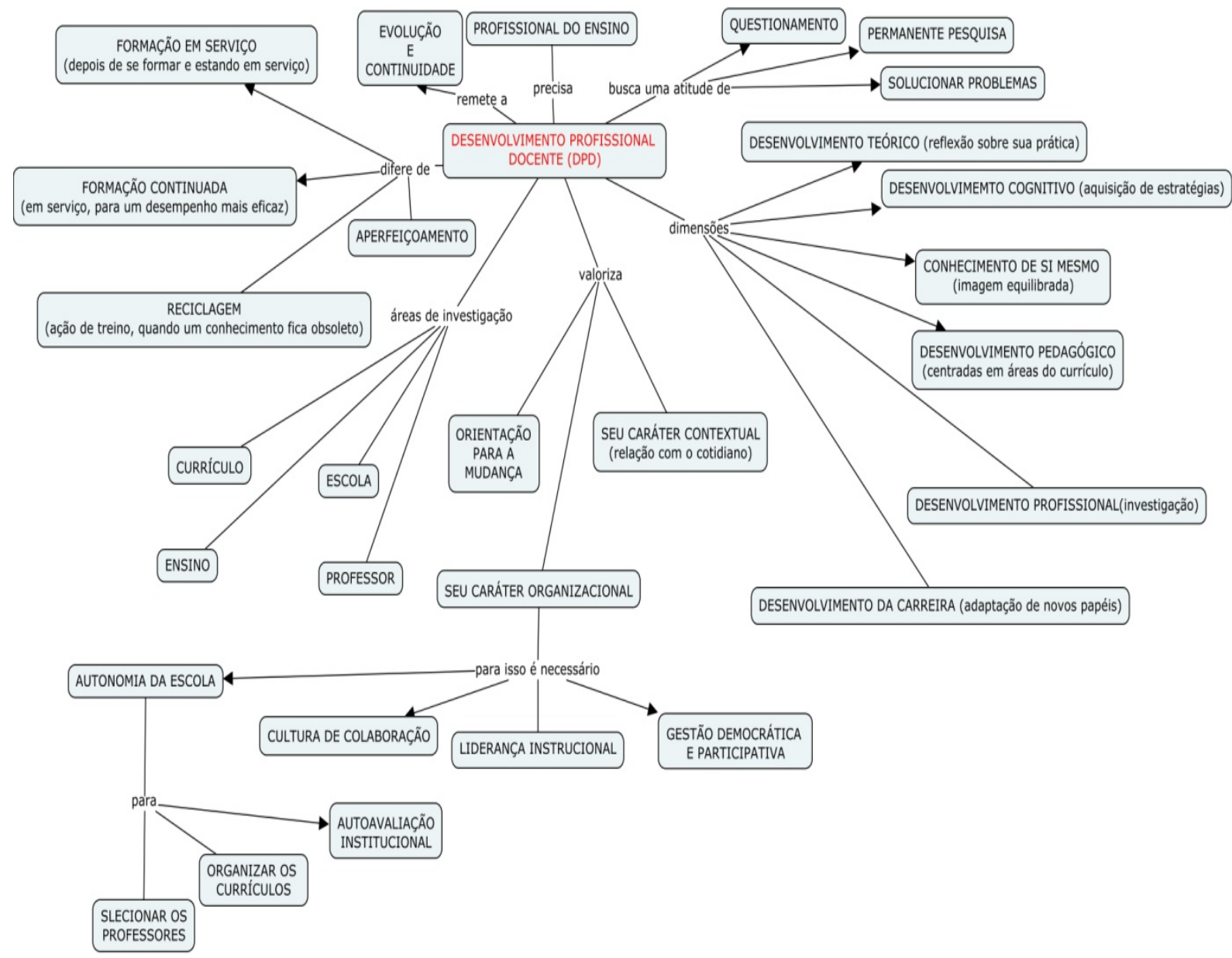

Fonte: Elaborado pela autora deste trabalho

Assim, tentamos nesse mapa conceitual entrelaçar as principais ideias apresentadas pelos autores em relação ao DPD, suas áreas de investigação, suas dimensões, suas buscas, no intuito de sistematizar os conceitos que fundamentam e esclarecem a temática apresenta.

\section{CONSIDERAÇÕES FINAIS}

Reiterando as reflexões abordadas bem como as discussões pautadas nesse trabalho, é importante compreender que tanto a Formação Inicial do Professor quanto a Formação Continuada compõem parte do Desenvolvimento Profissional Docente (DPD); o que poderá 
ocorrer ao longo de sua carreira como professor; caracterizada por sempre estar em movimento dialético e em constante aprimoramento. Vale destacar que o professor não pode e não deverá estar aquém de atualizações permanentes; mas, essencialmente, além de uma vivência pedagógica a qual o tornará um profissional diferenciado e valorizado tanto por alunos como por seus pares. Ademais, quanto mais capacitado e habilitado em sua carreira docente, mais segurança ele terá para desempenhar, com eficiência e eficácia, o papel de professor, dentro ou fora dos muros dos espaços escolares. Vale dizer, ainda, que professor preparado é sinônimo de profissional estimulado e preparado a enfrentar inúmeros desafios que a própria Educação lhe dispõe.

Assim sendo, é notório perceber que, para que o DPD seja eficaz, ele deve ter uma relação dialética entre teoria e prática; o que não poderiam ser consideradas apenas aquelas oficinas que acontecem de tempos em tempos sem nenhuma contribuição para as melhorias e as mudanças na prática docente. Nem muito menos debates inócuos, oriundos e definidos pelas Secretarias de Governo; elaborados sem a participação docente; sem o envolvimento de seus principais atores. Talvez, seja o momento propício em se pensar em estratégias mais pontuais e bem mais interativas e colaborativas no sentido de dar uma maior efetividade às chamadas "Reuniões de Planejamento", ou outro nome a que se queira denominar.

Consideramos importante destacar que, na busca pela formação do professor, além da prática reflexiva, o construto a partir de etapas passadas, podem ser fundamentais para subsidiar as discussões sobre a relação entre os conhecimentos teóricos e os práticos.

Portanto, ao se propor discussões sobre a formação de professores, não podemos deixar de citar três necessidades importantes: a primeira, trata-se da necessidade de mudanças relacionadas às políticas públicas que organizam e promovem o desenvolvimento profissional. A segunda se refere à necessidade de uma conscientização dos professores em relação a tal conceito, já que muitos docentes, quando buscam esse desenvolvimento, esperam receitas prontas para que possam ser aplicadas em sala de aula; e, principalmente, mecanismos que atenda às suas necessidades momentâneas. Já outros buscam-no apenas para terem o acréscimo aos salários; não se atentando ou não compreendendo a importância que a formação tem para si ou si mesma. E, terceira, a necessidade de as próprias Instituições, as quais fornecem esse tipo de formação, possam visualizar a sua relevância para a construção de um projeto que 
vislumbre saberes disciplinares, curriculares e experiências mais exequíveis; isto é, aspectos extremamente defendidos pelas novas Diretrizes Curriculares.

Nesse sentido, Alvarado Prada (1997, p. 91), cita algumas dificuldades que os "Cursos" enfrentam quanto à Formação para Professores. Ele aponta a falta de uma política de "Cursos", em nível local que garanta a continuidade dos processos; a não valorização do profissional da Educação como também da profissão docente; os Cursos os quais não atendem aos interesses dos docentes, os quais sempre ocorrem fora do contexto escolar; Cursos que se realizam com recursos dos próprios professores; a pouca participação coletiva dos envolvidos, dentre outras. Aqui, há de se ressaltar que, em nossa percepção, enquanto tais dificuldades não forem minimamente sanadas, a Educação continuará, infelizmente, sendo vista como coadjuvante nesse processo; servindo-se apenas como mais uma estatística a ser apresentada aos órgãos internacionais. Ainda, nessa mesma direção, acreditamos que, enquanto as propostas apresentadas pelas DCN's (Diretrizes Curriculares Nacionais) não forem tiradas do papel, há de se conviver com a falácia da Educação bem como os fracassos de nossos educandos. $\mathrm{Na}$ prática, o que se assiste é que não há investimentos a curto ou a longo prazo; nem um esforço conjunto a fim de reverter o atual cenário de formação inadequada em todos os âmbitos educacionais.

Somos cientes e conscientes de que a formação e o desenvolvimento profissional é um processo que exige envolvimento e dedicação tanto de professores, Instituições de Ensino; e, essencialmente, quanto à aplicação efetiva de políticas públicas eficazes que regem todo esse sistema. Nessa linha de pensamento, Gatti (2015, p. 166) afirma que "hoje as estruturas formativas de professores, seus conteúdos, as didáticas estão todos eles colocados como um enorme problema político e social”; o que, em nosso entendimento, há uma razão para se pensar desse modo; já que aos olhos de órgãos governamentais quanto menos criticidade a população se apresentar, mais facilidade encontrarão para "driblar" os procedimentos necessários a se presenciar e a viver uma Educação digna do povo brasileiro

Mediante tantos aspectos que, segundo Gatti (2015), são fundamentais na busca de uma formação sólida do professor, entendemos que, realmente, o desenvolvimento profissional docente é tido como um desafio a ser enfrentado. O que desejamos é que o professor seja um profissional dinâmico, dotado de várias habilidades, capaz de resolver problemas; despertando 
e motivando o interesse do aluno. E, em sua atuação, trabalhe temas atuais, temas transversais; que saiba usar as ferramentas de tecnologia assim como os instrumentos das mídias digitais no sentido de buscar mais atualidade em sua prática docente.

Aqui, cabe mais um questionamento: os Cursos de Formação Inicial estão preparados para conseguir agregar todas essas propostas de mudança e as apresentadas pelas DCN's? Para tentar buscar uma resposta, recorremos, novamente, a Gatti (2015, p.166) que ressalta que "a estrutura e o desenvolvimento curricular das licenciaturas... não têm mostrado inovações e avanços que permitam ao licenciado enfrentar o início de uma carreira docente com uma base consistente de conhecimentos". E, vale continuar com Azevedo (2012, p. 02) o qual aponta que, apesar de nos últimos 40 anos a formação de professores ser um dos principais assuntos discutidos no âmbito da educação, "a formação oferecida permanece sem alterações significativas"; e, acrescenta que há de haver a necessidade urgente de uma reformulação nos Cursos de Formação Inicial como também nos de Formação Continuada. Isso significa afirmar outra vez que a formação e o desenvolvimento profissional docente é uma emergência hoje no país, dadas as circunstâncias adversas que se tem na Educação Brasileira. Reafirmamos que tal necessidade é premente e urgente para que não venhamos a assistir a uma completa degradação tanto de professores, alunos, ensino; enfim, todos os envolvidos nesse processo.

Após as reflexões e discussões apresentadas, consideramos que talvez fosse pertinente voltarmos à pergunta inicial, a qual nos instigou à elaboração desse trabalho, focada por Fiorentini e Crecci (2013): “O DPD é um termo guarda-chuva ou um novo conceito?”.

Acreditamos que o Desenvolvimento Profissional Docente não possa ser um termo guarda-chuva, por apenas abrigar vários conceitos. Tal termo vai muito além de aperfeiçoamento, reciclagem, formação continuada ou qualquer outro termo já usado com esse sentido. Entendemos que seja algo mais abrangente; que possa ser uma rede, um entrelaçamento de conceitos que se relacionam e se inter-relacionam; que dialogam e estabelecem diálogos produtivos, cuja finalidade precípua seja a busca por transformações do profissional docente bem como daqueles que irão usufruir de tais benefícios.

Finalizando, cabe afirmar que, com este trabalho, não se tem a intenção de esgotar completamente a temática discutida. Como os próprios autores, inclusive os citados neste estudo, sugerem que quanto mais busquemos por melhor compreender os temas refletidos e 
discutidos por estudiosos e pesquisadores sobre a temática em pauta, mais questionamentos se evidenciarão. E, na busca por possíveis respostas, quiçá, poderemos encontrar um novo conceito ou um novo termo; o que, se for encontrado e aplicado no cotidiano docente, um cenário diferente do atual possa surgir; não somente para a formação de professores, mas, sobretudo, uma realidade nova; uma realidade de melhoria na qualidade da Educação.

\section{REFERÊNCIAS}

ALMEIDA, Célia Maria de Castro. A problemática da formação de professores e o mestrado Em educação da Uniube. Revista profissão docente (online), Uberaba, v.1, n.1, fev. 2001, p.02-04.

ALVARADO PRADA, Luis Eduardo. Formação de Docentes em Serviço. In: Formação participativa de docentes em serviço. Taubaté, SP: Cabral Editora Universitária, 1997. p. 87-103.

AZEVEDO, R.O.M. et al. Formação inicial de professores da educação básica no Brasil: trajetória e perspectivas. Rev. Diálogo Educ., Curitiba, v.12, n.37, p.997-1026, set./dez.2012.

BRASIL.CNE. Resolução $N^{\circ} 2$, de $1^{\circ}$ de julho de 2015. Diretrizes Curriculares Nacionais para a formação inicial em nível superior. Disponível em: http://portal.mec.gov.br/index.php?option=comdocman\&view=download\&alias=17719-rescne-cp-002-03072015\&categoryslug=julho-2015-pdf\&Itemid=30192

DOURADO, L.F. Diretrizes curriculares nacionais para a formação inicial e continuada dos profissionais do magistério da educação básica: concepções e desafios. Educ. Soc., Campinas, v.36, $\quad \mathrm{n}^{\circ} 131, \mathrm{p} .299-324$,abri.-jun.,2015. Disponível em: http://www.scielo.br/pdf/es/v36n131/1678-4626-es-36-131-00299.pdf

FIORENTINI, D.; CRECCI, V. Desenvolvimento Profissional Docente: um termo guardachuva ou um novo sentido à formação? Revista Brasileira sobre Formação Docente. Belo Horizonte. V.5, p. 11 a 23, jan/jul/2013. Disponível em: http://formacaodocente.autenticaeditora.com.br

GATTI, B.A. Formação de professores: condições e problemas atuais. Revista Brasileira de formação de Professores - RBFP. Vol. 1, n.1, p.90-102, maio/2009. Disponível em: HTTPS://itp.ifsp.edu.br/ojs/index.php/RIFP/article/dowload/347/360

MARCELO Garcia, Carlos. Estrutura Conceptual da Formação de professores. In: Formação de Professores: para uma mudança educativa. Lisboa: Porto Editora. 1999, p. 17 33.

Desenvolvimento Profissional dos Professores. In: 
1999, p. 136-145.

Formação de Professores: para uma mudança educativa. Lisboa: Porto Editora.

MELLO, S.A; LUGLE, A.M.C. Formação de professores: implicações pedagógicas da Teoria Histórico-Cultural. Revista Contrapontos-Eletrônica, v.14, n.2, maio/ago 2014. Disponível em: http://siaiap32.univali.br/seer/index.php/rc/article/view/4763/pdf 31

PRADO, A.F. et al. Ser professor na contemporaneidade: desafios da profissão. Disponível em: https://www.inesul.edu.br/revista/arquivos/arq-idvol_1373923960.pdf. Acesso em: 26/03/17.

SILVA, A.L.S. Mapas conceituais no processo ensino-aprendizagem: aspectos práticos. Disponível em: http://www.infoescola.com/pedagogia/mapas-conceituais-no-processo-deensino-aprendizagem-aspectos-praticos/. Acesso em: 28/03/17.

VEIGA, Ilma Passos Alvarenga. Ensinar, aprender, e avaliar com mapas conceituais. In: (org.). Novas tramas para as técnicas de ensino e estudo. Campinas. SP: Papirus 2013. 